\title{
Comparison of the biopsy and cytobrush techniques for diagnosis of subclinical endometritis in mares
}

\author{
Justyna Buczkowska', Roland Kozdrowski ${ }^{*}$, Marcin Nowak' ${ }^{1}$ Andrzej Raś', Zdzisław Staroniewicz' \\ and Marta J Siemieniuch ${ }^{3}$
}

\begin{abstract}
Background: Endometritis is a major cause of infertility in the mare. Therefore, the diagnosis of this disease is very important in veterinary practice. The objective of this study was to compare bacteriological and cytological results obtained from the mare uterus using biopsy (EB) and cytobrush (CB) techniques and relating these findings to the presence of polymorphonuclear cells (PMNs) in endometrial tissue as the gold standard for detection of endometritis. In particular, we tested the hypothesis that endometrial cytology and microbiology data obtained from material collected using the $E B$ and $C B$ techniques are similar, so that the $C B$ technique could preferentially be used to detect subclinical endometritis in clinical practice.

Methods: A total of 69 mares suspected of subclinical endometritis because of previous reproductive history and 15 maiden mares were enrolled in this study. Material collected from both EB and CB was smeared on sterile glass slides for cytological examinations and on culture media for microbiological examinations. Bacteriological cultures and cytological samples were classified as negative (no growth or mixed cultures of more than three microorganisms; $<2 \%$ PMNs) or positive (pure growth of microorganisms; $>2 \%$ PMNs) for endometritis.
\end{abstract}

Results: Positive growth was observed in $43 \%$ of CB samples and in $54 \%$ of EB samples (difference not significant). The growth of $\beta$-hemolytic streptococci was always connected with positive cytology. This relationship was not observed for growth of E. coli or for non-pathogenic flora. The sensitivity of bacterial growth and cytology from EB was 0.63 and 0.73 respectively. The sensitivities of bacterial growth and cytology from CB were 0.50 and 0.71 respectively.

Conclusion: Microbiological and cytological results obtained from CB are similar to those obtained from EB and based on these findings the CB technique may be recommended for collection of materials from the mare's uterus in clinical practice.

Keywords: Mare, Endometritis, Biopsy, Cytobrush, Cytology

\section{Background}

Endometritis is a major cause of infertility in the mare [1-4]. Therefore the diagnosis of this disease is very important in veterinary practice [5]. Useful methods for the diagnosis of endometritis include clinical examination, transrectal palpation and ultrasonography of the reproductive tract, vaginal speculum examination, uterine culture,

\footnotetext{
* Correspondence: roland.kozdrowski@up.wroc.pl

${ }^{1}$ Faculty of Veterinary Medicine, Wrocław University of Environmental and Life Sciences, Wrocław, Poland

Full list of author information is available at the end of the article
}

cytology and endometrial biopsy [2,3,5-7]. Mares suffering from subclinical endometritis usually do not show the typical symptoms associated with endometritis, i.e. accumulation of fluid in the uterus, and therefore the last three aforementioned tests to detect the disease are additionally required. Subclinical endometritis is influenced by the type of pathogen and the mare's subsequent immunological response [3,7]. Endometritis is most commonly associated with aerobic bacteria [5]. However, isolation of bacteria does not necessarily prove the presence of endometritis nor does failure to isolate bacteria eliminate it $[5,8,9]$. It is 
believed that the combination of cytological and bacteriological diagnostics increases the ability to detect endometritis [5,7]. Moreover, the advantage of cytology is the ability to obtain results as early as the day of collection, while for bacteriological examination it takes $48-72 \mathrm{~h}$ from the time of sample collection [1,5,10-13]. Bourke and colleagues [14] compared the double guarded cotton swab (CS) and the uterine cytobrush (CB) techniques and showed that the latter was a superior method for collection of endometrial samples. More cases of endometritis are detected using CB than using the CS technique $[7,13,15]$. Moreover, higher sensitivity of the bacteriological test was reported after a biopsy had been examined [11].

To determine the relative importance of bacterial culture vs. cytology, it is helpful to have a gold standard for the presence or absence of disease against which the results can be compared. Many authors used as the gold standard the presence of neutrophil infiltration of the luminal epithelium and stratum compactum in uterine biopsies $[11,16,17]$. Endometrial biopsy is safe and useful, but not a particularly practical technique that allows an accurate assessment of the endometrium $[8,18,19]$. However, the histopathology is characterized by a long time waiting for the results and the special tools are needed for biopsy collection.

Previously, routine sampling of the mares uterus depended on the use of CS, while today the CB is used more frequently in the diagnosis of endometritis. Therefore, the objective of this study was to compare bacteriological and cytological results obtained from the mare uterus using both the biopsy (EB) and $\mathrm{CB}$ techniques and relating these findings to the presence of polymorphonuclear cells (PMNs) in endometrial tissue for the detection of endometritis. In particular, we tested the hypothesis that endometrial cytology and microbiology data obtained from material collected using the $\mathrm{EB}$ and $\mathrm{CB}$ techniques are similar, so that the $\mathrm{CB}$ technique could preferentially be used to detect subclinical endometritis in clinical practice.

\section{Methods}

\section{Ethical approval for the use of animals}

This study was approved by II Local Ethics Committee in Wrocław (Wrocław University of Environmental and Life Sciences, Poland). Reference number of approval: 43/2011, date: 18 April 2011.

\section{Animals}

The study was conducted between February and September 2012 at a number of stud farms in Poland. The material was collected from 69 mares suspected of subclinical endometritis (aged 6-23 years) and from 15 maiden mares (young, aged 3-4 years, with no history of breeding). Mares suspected of subclinical endometritis had been bred three or more times unsuccessfully in the same breeding season, or had a history of one year of reproductive failure. Some of these mares had been treated with intrauterine antibiotic infusions in a previous breeding season and despite the treatment had not become pregnant. All mares were examined by transrectal palpation and ultrasonography for genital health and determination of cycle stage. None of the mares included in the study showed fluid in the uterus. Thirtyseven mares were in oestrus (exhibiting endometrial oedema and a dominant follicle) and 45 mares were in dioestrus (they showed no endometrial oedema and had a corpus luteum).

\section{Sample collection}

Prior to sample collection, the mare's tail was bandaged, the vulva and perineum were scrubbed with povidoneiodine and dried with a paper towel. An endometrial biopsy was collected using a sterilized biopsy punch (Equi-Vet, Kruuse; Denmark). Additionally, the biopsy punch was covered by a sanitary sleeve (Equi-Vet, Kruuse; Denmark). The instrument was passed through the vagina and cervix into the uterus with a sleeved and lubricated arm. After the forceps were placed in the uterine lumen, the arm was withdrawn from the vagina and inserted into the rectum to guide the forceps to the desired location. The uterine biopsy was taken from the base of the uterine horn.

Immediately after biopsy collection, the vulva and perineum were again cleaned and cellular material was collected from each mare using a commercially available CB (Cytology Brush; Minitube GmbH, Germany). The instrument was passed through the vagina and cervix into the uterus with a sleeved and lubricated arm. Cellular material was always collected from the base of the uterine horn opposite the site of biopsy collection by rotating the CB. The EB was always obtained before collection of cellular material similar to the protocol used by Nielsen [11].

Samples of EB and CB were immediately smeared on a sterile glass slide to obtain a cytological sample and afterwards were smeared onto culture media for microbiological examination. Finally, the end EB samples were fixed in formaldehyde for histopathological examination.

\section{Microbiology}

All samples (from CB and EB) were smeared on a blood agar and also on Brain Heart Infusion Agar and on selective media: Eosin Methylene Blue Agar, Mannitol Salt Agar, Sabouraud Dextrose Agar. All culture media were obtained from Oxoid Ltd., Basingstoke; Hampshire, England. Culture media were incubated at $37^{\circ} \mathrm{C}$ in atmospheric air and after 24 hours growth of microorganisms was recorded. Culture plates with no growth were incubated and re-examined at 48 and 72 hours for the presence of 
bacteria or yeast. If $>90 \%$ of the cultured colonies were of one species, they were considered to be a monoculture. Mixed cultures of more than three pathogens were considered as contamination $[7,11]$. A commercially available biochemical reaction system API was used, if further typing of cultures were needed. The common bacteria: $\beta$-hemolytic Streptococcus, E. coli, Corynebacterium spp. and Pseudomonas spp. were considered as equine uterine pathogens. Non-pathogenic bacteria were recorded only if isolated in pure culture [17].

\section{Cytology}

After sampling and preparing the smears, the cytological specimens were fixed with Cytofix (Samko, Dobczyn; Poland) and stained using Diff Quick stain (Medion Diagnostics AG, Düdingen; Switzerland). The presence of PMNs was examined with light microscopy under oil immersion (1000× magnification). When PMN-cells represented more than $2 \%$ of all cells in the sample, it was considered positive for endometritis $[7,20]$. In each sample, 300 cells were counted.

\section{Histopathology}

Endometrial biopsies were fixed in formalin and stained with haematoxylin and eosin. Biopsy specimens were evaluated by light microscopy for the presence of PMNinfiltration of the endometrial luminal epithelium and the stratum compactum. If one or more PMNs per five fields (400× magnification) occurred, the sample was considered as positive for endometritis [11,21].

\section{Statistical analysis}

All comparisons were made by a Chi-square test and significance was set at $P<0.05$. Microbiological and cytological results obtained from $\mathrm{EB}$ and $\mathrm{CB}$ were related to the histopathological presence of PMNs in the endometrium. Sensitivity, specificity, and positive and negative predictive value for these diagnostic tests were calculated. The sensitivity is the percentage of ill patients correctly diagnosed. The specificity is the percentage of healthy patients correctly diagnosed. The positive predictive values is the probability that positive results are really true, and the negative predictive values is the probability that negative results are really true. The sensitivity was calculated as the proportion of true positive results to true positive and false negative results. The specificity was calculated as the proportion of the true negative results to true negative and false positive results. The positive predictive value was calculated as the proportion of the true positive results to true positive and false positive results. The negative predictive value was calculated as the proportion of the true negative results to true negative and false negative results. True positive results are the number of mares with positive histopathology and positive cytology or microbiology (correctly identified). True negative results are the number of mares with negative histopathology and negative cytology or microbiology (correctly rejected). False positive results are the number of mares with positive cytology or microbiology but with negative histopathology (incorrectly identified) and false negative results are the number of mares with negative cytology or microbiology but with positive histopathology (incorrectly rejected).

\section{Results}

Two cytological samples were not adequate for evaluation (hypocellularity). Consequently, cytological, bacteriological and histopathological specimens were examined and compared in 82 mares.

\section{Histopathological findings}

A total of 56 (68.3\%) mares had positive histopathology, including three maiden mares.

\section{Microbiological and cytological findings}

Results of uterine culture are shown in Figure 1. Positive growth from CB was obtained in 35 (43\%) of all mares and in 44 (54\%) from EB. We found no statistical differences in the number of positive cultures between $\mathrm{CB}$ and $\mathrm{EB}$.

In 44 of $82(54 \%)$ cytological smears obtained from $\mathrm{CB}$ and in 42/82 (51\%) of cytological smears obtained from EB the percentage of PMNs was above $2 \%$. This difference was not significant. Relationships between microorganisms and cytological findings are shown in Table 1 . Both in CB and EB, $32 \%$ of cytologically positive mares also had positive cultures. The most common pathogenic bacteria cultured from $\mathrm{EB}$ and from $\mathrm{CB}$ were $\beta$-hemolytic streptococci,

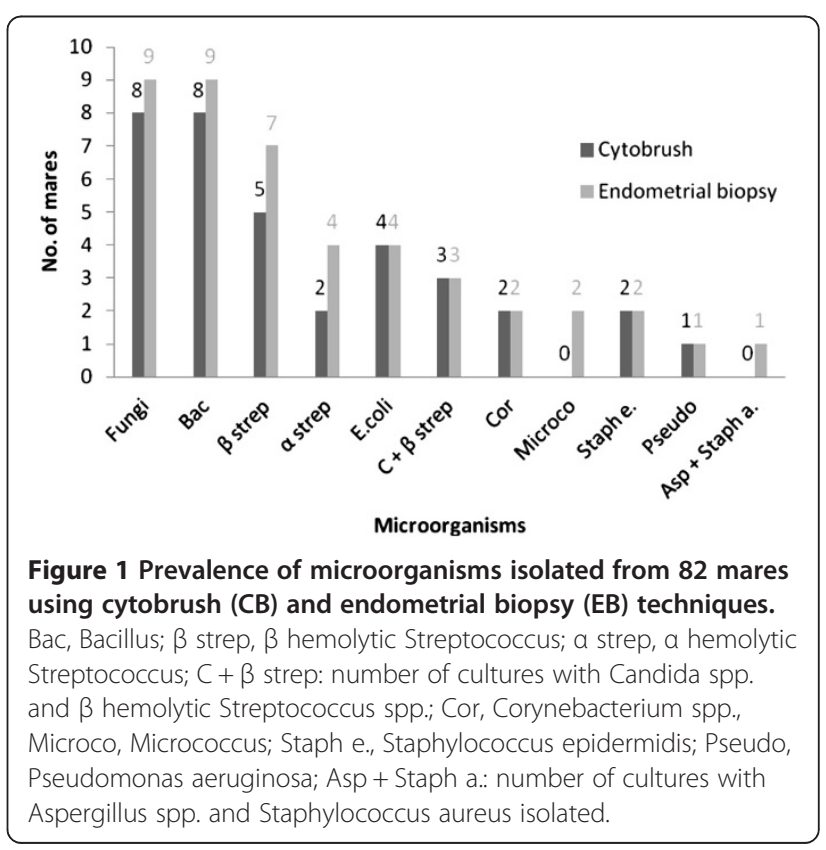


Table 1 Relationship between microorganisms isolated and cytological findings

\begin{tabular}{|c|c|c|c|c|c|c|}
\hline \multirow[t]{2}{*}{ Microorganisms } & \multicolumn{3}{|c|}{ Cytobrush } & \multicolumn{3}{|c|}{ Endometrial biopsy } \\
\hline & $\begin{array}{c}\text { Number of } \\
\text { smears with } \\
\text { negative } \\
\text { cytology }\end{array}$ & $\begin{array}{c}\text { Number of } \\
\text { smears with } \\
\text { positive } \\
\text { cytology }\end{array}$ & $\begin{array}{c}\text { Concordance } \\
\text { between } \\
\text { cytology and } \\
\text { microbiology (\%) }\end{array}$ & $\begin{array}{c}\text { Number of } \\
\text { smears with } \\
\text { negative } \\
\text { cytology }\end{array}$ & $\begin{array}{c}\text { Number of } \\
\text { smears with } \\
\text { positive } \\
\text { cytology }\end{array}$ & $\begin{array}{c}\text { Concordance } \\
\text { between } \\
\text { cytology and } \\
\text { microbiology (\%) }\end{array}$ \\
\hline B-hemolytic Streptococcus & 0 & 5 & $5 / 5(100)$ & 0 & 7 & $7 / 7(100)$ \\
\hline a-hemolytic Streptococcus & 2 & 0 & $0 / 2(0)$ & 3 & 1 & $1 / 4(25)$ \\
\hline E.coli & 2 & 2 & $2 / 4(50)$ & 3 & 1 & $1 / 4(25)$ \\
\hline Fungi & 0 & 8 & $8 / 8(100)$ & 4 & 5 & $5 / 9(56)$ \\
\hline Bacillus spp. & 4 & 4 & $4 / 8(50)$ & 6 & 3 & 3/9 (33) \\
\hline Corynebacterium spp. & 0 & 2 & $2 / 2(100)$ & 0 & 2 & $2 / 2(100)$ \\
\hline Pseudomonas aeruginosa & 0 & 1 & $1 / 1(100)$ & 1 & 0 & $0 / 1(0)$ \\
\hline Micrococcus spp. & 0 & 0 & 0 & 0 & 2 & $2 / 2(100)$ \\
\hline Staphylococcus epidermidis & 1 & 1 & $1 / 2(50)$ & 1 & 1 & $1 / 2(50)$ \\
\hline Candida $+\beta$ hemolytic Streptococcus & 0 & 3 & $3 / 3(100)$ & 0 & 3 & $3 / 3(100)$ \\
\hline Aspergillus + Staphylococcus aureus & 0 & 0 & 0 & 0 & 1 & 1/1 (100) \\
\hline
\end{tabular}

which was always associated with positive cytological findings. In $11 \%$ of samples collected using the CB technique, microbiology was positive but cytology was negative, but the isolated bacteria were E. coli or nonpathogenic species. In $22 \%$ of biopsy samples microbiology was positive but cytology was negative; E. coli, Pseudomonas aeruginosa and some non-pathogenic micro-organisms were cultured. Positive cytology was found in five maiden mares (from CB samples), and in three of these mares Bacillus was isolated.

\section{Relationships of microbiological and cytological findings obtained from EB and CB to histopathology}

Sensitivity, specificity, positive predictive value and negative predictive values of microbiological and cytological results obtained from EB and CB are presented in Table 2. Using the presence of PMN infiltration of the endometrial luminal epithelium and the stratum compactum as the gold standard for diagnosis of endometritis, the sensitivity of cytology from CB was 0.71 and from EB 0.73 and the sensitivity of microbiology from $\mathrm{CB}$ was 0.50 and from $\mathrm{EB}$ 0.63 . When we combined results of cytological and bacteriological examinations, the sensitivity for both EB and CB increased (Table 3).

\section{Discussion}

The types of microorganisms isolated from the uterus of mares in this study were similar to those reported in other studies $[5,11,17,22,23]$. However, in our study the most frequently isolated bacterium both from EB and CB was Bacillus which is considered to be non-pathogenic. Also in studies conducted by LeBlanc and colleagues [17] and Riddle and colleagues [5] non-pathogenic bacteria were frequently isolated. In our study, the growth of Bacillus was occasionally associated with positive cytology. Similarly, in studies conducted by LeBlanc and colleagues [17] and Riddle and colleagues [5], the isolation of Bacillus and other non-pathogenic species from the mare uterus was sometimes associated with positive cytology. The role of non-pathogenic bacteria isolated from the mare uterus is still unknown, however, some studies showed a possible association of these bacteria with decreased pregnancy rates [5]. We also rather frequently found fungi in materials collected using both $\mathrm{CB}$ and EB. This is not surprising if we take into consideration that most of the mares with growth of fungi had a history of frequently repeated intrauterine infusions of antibiotics in the previous breeding season. Similar to other studies, the most common pathogenic bacteria cultured from both EB and CB was $\beta$-hemolytic Streptococcus $[5,11,23]$.

It should be noted that we found no statistical differences in the number of positive cultures between $C B$ and $\mathrm{EB}$ or in positive cytology findings between $\mathrm{CB}$ and $\mathrm{EB}$. In a study conducted by Overbeck and colleagues [7], bacteriological findings were not associated with positive cytology. In our study, isolation of $\beta$-hemolytic streptococci both in pure growth or in mixed growth with Candida was always associated with positive cytology. This relationship was also observed for the growth of Corynebacterium spp. but not for E. coli. Similarly in other studies, isolation of $\beta$-hemolytic streptococci was most commonly associated with positive cytology, and isolation of $E$. coli and other gram-negative bacteria was more likely not to associate with cytological evidence of inflammation [5,12]. 
Table 2 Sensitivity, specificity, positive and negative predictive values data of cytological and microbiological examinations from cytobrush (CB) and endometrial biopsy (EB)

\begin{tabular}{|c|c|c|c|c|c|c|c|}
\hline & Histology positive & Histology negative & Sum & Sensitivity & Specificity & $\begin{array}{c}\text { Positive } \\
\text { predictive value }\end{array}$ & $\begin{array}{c}\text { Negative } \\
\text { predictive value } \\
\end{array}$ \\
\hline Microbiology of EB positive & 35 & 12 & 47 & 0.63 & 0.54 & 0.74 & 0.40 \\
\hline Microbiology of EB negative & 21 & 14 & 35 & & & & \\
\hline Sum & 56 & 26 & 82 & & & & \\
\hline Microbiology of $C B$ positive & 28 & 7 & 35 & 0.50 & 0.73 & 0.80 & 0.40 \\
\hline Microbiology of $C B$ negative & 28 & 19 & 47 & & & & \\
\hline Sum & 56 & 26 & 82 & & & & \\
\hline Cytology of EB positive & 41 & 1 & 42 & 0.73 & 0.96 & 0.98 & 0.63 \\
\hline Cytology of EB negative & 15 & 25 & 40 & & & & \\
\hline Sum & 56 & 26 & 82 & & & & \\
\hline Cytology of CB positive & 40 & 4 & 44 & 0.71 & 0.85 & 0.91 & 0.58 \\
\hline Cytology of $C B$ negative & 16 & 22 & 38 & & & & \\
\hline Sum & 56 & 26 & 82 & & & & \\
\hline
\end{tabular}

It was shown in hysteroscopic examinations that $E$. coli can occur in local areas which can explain some of the failures to diagnose E. coli [17]. Walter and colleagues [15] found significant association between the number of colonies of $\beta$-hemolytic streptococci and the number of PMNs in smears, but this association was not observed for other microorganisms. LeBlanc and colleagues [17] suggested that the pathogenicity of $E$. coli appears to be different from pathogenicity of $\beta$-hemolytic Streptococcus, and consequently the uterine inflammatory response can vary with different microorganisms.

In our study, a total of $56(68.3 \%)$ mares had positive histopathology, including three young mares. As indicated by the presence of PMNs in endometrial tissue the sensitivity of cytology obtained from $E B$ and $C B$ was superior to the sensitivity of microbiological examinations from both $\mathrm{EB}$ and $\mathrm{CB}$. These results showed that cytological examination is more accurate than microbiology for diagnosis of inflammation of the endometrium. Also in another study, positive cytology was twice as common as a positive culture [5]. Additionally, cytological examinations of samples collected using the EB or $\mathrm{CB}$ techniques had higher positive predictive value than bacteriological examination with both sampling methods. This demonstrates that cytological examination is a more accurate method for diagnosis of endometritis than bacteriology and any positive cytology should be considered with high probability as indicative of endometritis. However, we must remember that this technique does not provide information about a cause of the inflammation.

The sensitivity of bacterial growth from EB presented in our study was lower than that estimated by Nielsen [11]. In contrast, the sensitivity of microbiology and cytology obtained both from EB and CB was much higher than in the study conducted by Overbeck and colleagues [7]. Additionally, in our study the specificity of bacterial growth from $\mathrm{CB}$ was higher than from EB, most likely because of the reduced risk of contamination of the sample collected using CB.

When we combined the results of cytological and bacteriological examinations, the sensitivity increased. Overbeck and colleagues [7] also showed that the combination of cytological and bacteriological examination of endometrial samples collected using $\mathrm{CB}$ might be the most promising approach for diagnosing endometritis.

Table 3 Sensitivity, specificity, positive and negative predictive values data of the combination of cytological and microbiological examinations from cytobrush (CB) and endometrial biopsy (EB)

\begin{tabular}{|c|c|c|c|c|c|c|c|}
\hline & $\begin{array}{c}\text { Histology } \\
\text { positive }\end{array}$ & $\begin{array}{c}\text { Histology } \\
\text { negative }\end{array}$ & Sum & Sensitivity & Specificity & $\begin{array}{c}\text { Positive } \\
\text { predictive value }\end{array}$ & $\begin{array}{c}\text { Negative } \\
\text { predictive value } \\
\end{array}$ \\
\hline Microbiology and cytology of EB positive & 51 & 12 & 63 & 0.91 & 0.54 & 0.81 & 0.74 \\
\hline Microbiology and cytology of EB negative & 5 & 14 & 19 & & & & \\
\hline Sum & 56 & 26 & 82 & & & & \\
\hline Microbiology and cytology of CB positive & 48 & 8 & 56 & 0.86 & 0.69 & 0.86 & 0.69 \\
\hline Microbiology and cytology of $C B$ negative & 8 & 18 & 26 & & & & \\
\hline Sum & 56 & 26 & 82 & & & & \\
\hline
\end{tabular}




\section{Conclusions}

The long time between sampling and laboratory results is a practical disadvantage of the biopsy approach while results of cytology are rapid. A biopsy is not always possible, but $\mathrm{CB}$ is a quick, relatively inexpensive and safe technique, easy to obtain under field conditions and enables the diagnosis of subclinical endometritis. Consequently, based on our results we can recommend the $\mathrm{CB}$ technique for diagnosis of subclinical endometritis in the mare, when the samples are collected during oestrus or dioestrus and examined both cytologically and microbiologically.

\section{Abbreviations}

CB: Cytobrush; EB: Endometrial biopsy; PMNs: Polymorphonuclear cells.

\section{Competing interests}

The authors declare that they have no competing interests.

\section{Authors' contributions}

JB contributed to sample collection, cytological analysis, analysis of the results and writing the manuscript. RK contributed in conceiving the study, sample collection, cytological analysis, analysis of the results and writing the manuscript. MN contributed by histopathological examination. AR contributed in conceiving the study and sample collection. ZS contributed by microbiological examination, and MJS contributed in conceiving the study and sample collection. All authors read and approved the final manuscript.

\section{Acknowledgments}

This study was supported by the grant of the NCN, DEC-2011/01/B/NZ5/ 04173.

Authors are indebted to Dr. Barry Bavister for help with editing this manuscript.

\section{Author details}

${ }^{1}$ Faculty of Veterinary Medicine, Wrocław University of Environmental and Life Sciences, Wrocław, Poland. 'Department and Clinic of Reproduction, Faculty of Veterinary Medicine, University of Warmia and Mazury, Olsztyn, Poland. ${ }^{3}$ Department of Reproductive Immunology and Pathology, Institute of Animal Reproduction and Food Research of the Polish Academy of Sciences, Olsztyn, Poland.

Received: 15 January 2014 Accepted: 31 March 2014 Published: 4 April 2014

\section{References}

1. Card C: Post-breeding inflammation and endometrial cytology in mares. Theriogenology 2005, 64:580-588.

2. Defontis M, Vaillancourt D, Grand FX: Comparison of three methods of sampling for endometrial cytology in the mare. Tierarztl Prax 2011 39:171-175.

3. LeBlanc MM, Causey RC: Clinical and subclinical endometritis in the mare: both threats to fertility. Reprod Domest Anim 2009, 44:10-22.

4. Liu IKM, Troedsson MHT: Diagnosis and treatment of endometritis in the mare: yesterday and today. Theriogenology 2008, 70:415-420.

5. Riddle WT, LeBlanc MM, Stromberg AJ: Relationships between uterine culture, cytology and pregnancy rates in a Thoroughbred practice. Theriogenology 2007, 68:395-402.

6. Cocchia N, Paciello O, Auletta L, Uccello V, Silvestro L, Mallardo K, Paraggio G, Pasolini MP: Comparison of the cytobrush, cottonswab and low-volume uterine flush techniques to evaluate endometrial cytology for diagnosing endometritis in chronically infertile mares. Theriogenology 2012, 77:89-98.

7. Overbeck W, Witte TS, Heuwieser W: Comparison of three diagnostic methods to identify subclinical endometritis in mares. Theriogenology 2011, 75:1311-1318.

8. Kenney RM: Cyclic and pathologic changes of the mare endometrium as detected by biopsy, with a note on early embryonic death. J Am Vet Med Assoc 1978, 172:241-262.
9. LeBlanc MM: Advances in the diagnosis and treatment of chronic infectious and post-mating-induced endometritis in the mare. Reprod Domest Anim 2010, 45:21-27.

10. Digby NJW: The technique and clinical application of endometrial cytology in mares. Equine Vet J 1978, 10:167-170.

11. Nielsen JM: Endometritis in the mare: a diagnostic study comparing cultures from swab and biopsy. Theriogenology 2005, 64:510-518.

12. Nielsen JM, Troedsson MH, Pedersen MR, Lehen-Jensen $H$ : Diagnosis of endometritis in the mare based on bacteriological and cytological examinations of the endometrium. Comparison of results obtained by swabs and biopsies. J Equine Vet Sci 2010, 30:27-30.

13. Kozdrowski R, Gumienna J, Sikora M, Andrzejewski K, Nowak M: Comparison of the cytology brush and cotton swab in the cytological evaluation of the endometrium in mares with regard to fertility. J Equine Vet Sci 2013, 33:1008-1011.

14. Bourke M, Mills JN, Barnes AL: Collection of endometrial cells in the mare. Aust Vet J 1997, 75:755-758.

15. Walter J, Neuberg KP, Failing K, Wehrend A: Cytological diagnosis of endometritis in the mare: investigations of sampling techniques and relation to bacteriological results. Anim Reprod Sci 2012, 132:178-186.

16. Reiswig JD, Threlfall WR, Rosol TJ: A comparison of endometrial biopsy, culture and cytology during oestrus and dioestrus in the horse. Equine Vet J 1993, 25:240-241.

17. LeBlanc MM, Magsig J, Stromberg J: Use of a low-volume uterine flush for diagnosing endometritis in chronically infertile mares. Theriogenology 2007, 68:403-412

18. Ricketts SW, Barrelet A: A retrospective review of the histopathological features seen in series of 4241 endometrial biopsy samples collected from UK Thoroughbred mares over a 25 year period. Pferdeheilkunde 1997, 13:525-530.

19. Snider TA, Sepoy C, Holyoak GR: Equine endometrial biopsy reviewed: observation, interpretation and application of histopathologic data. Theriogenology 2011, 75:1567-1581.

20. Ball BA, Shin SJ, Pattern VH, Lein DH, Woods GL: Use of a low-volume uterine flush for microbiologic and cytologic examination of the mares endometrium. Theriogenology 1988, 29:1269-1283.

21. Ricketts SW, Alonso S: Assessment of the breeding prognosis of mares using paired endometrial biopsy techniques. Equine Vet J 1991, 23:185-188.

22. Albihn A, Båverud V, Magnusson U: Uterine microbiology and antimicrobial susceptibility in isolated bacteria from mares with fertility problems. Acta Vet Scand 2003, 44:121-129.

23. Frontoso R, De Carlo E, Pasolini MP, van der Meulen K, Pagnini U, lovane G, De Martino L: Retrospective study of bacterial isolates and their antimicrobial susceptibilities in equine uteri during fertility problems. Res Vet Sci 2008, 84:1-6.

doi:10.1186/1477-7827-12-27

Cite this article as: Buczkowska et al:: Comparison of the biopsy and cytobrush techniques for diagnosis of subclinical endometritis in mares. Reproductive Biology and Endocrinology 2014 12:27.

\section{Submit your next manuscript to BioMed Central and take full advantage of:}

- Convenient online submission

- Thorough peer review

- No space constraints or color figure charges

- Immediate publication on acceptance

- Inclusion in PubMed, CAS, Scopus and Google Scholar

- Research which is freely available for redistribution 